\title{
Ações de sustentabilidade: práticas predominantes em um grupo de comércio varejista
}

\section{Lucelma Maria dos Santos Cunha', Maisa de Souza Ribeiro $^{2}$, Amaury José Rezende ${ }^{2}$ e Mariana Simões Ferraz do Amaral Fregonesi ${ }^{2}$}

\author{
${ }^{1}$ Universidade de São Paulo. Programa de Pós-Graduação em Controladoria e \\ Contabilidade. Faculdade de Economia, Administração e Contabilidade. Ribeirão \\ Preto-SP, Brasil. E-mail: lucelmac@usp.br. \\ ${ }^{2}$ Universidade de São Paulo. Faculdade de Economia, Administração e \\ Contabilidade. Departamento de Contabilidade. Programa de Pós-Graduação em \\ Controladoria e Contabilidade. Ribeirão Preto-SP, Brasil.
}

Resumo. A governança do meio ambiente tem se tornado um tópico central na discussão sobre os impactos das atividades produtoras e da gestão socioambiental. Em um contexto de verificação de práticas ambientais proativas e reativas, os relatórios anuais de um grupo empresarial varejista foram analisados com o objetivo de identificar as práticas de sustentabilidade predominantes do grupo, ocorridas de 2010 a 2017. Os dados foram analisados longitudinalmente e de forma qualitativa, por meio de análise interpretativa de ações relacionadas ao consumo de energia e água, ao descarte de água, à emissão de gases do efeito estufa (GEE) e à gestão de resíduos. Observou-se a predominância de práticas proativas operacionais, a exemplo de projetos de eficiência energética, medidas para a redução no consumo de água, substituição do uso de GEE e gestão de resíduos, internos e externos, além do desenvolvimento de ações que buscam conformidade legal. De forma geral, este estudo contribui para a identificação das ações ambientais internas e externas à instituição, passíveis de serem implementadas pelo setor varejista para reduzir os custos de impactos ambientais causados por suas operações e aperfeiçoar a gestão ambiental.

Palavras-chave: Práticas sustentáveis; Proatividade; Reatividade; Relatórios anuais; Varejo.

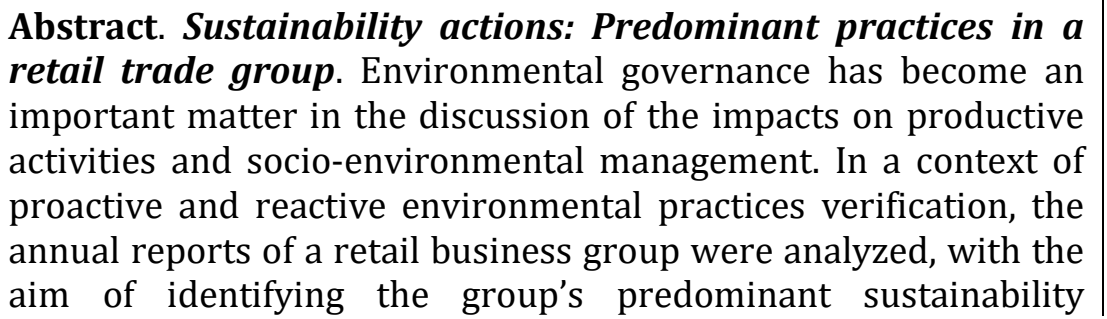

Abstract. Sustainability actions: Predominant practices in a retail trade group. Environmental governance has become an important matter in the discussion of the impacts on productive activities and socio-environmental management. In a context of proactive and reactive environmental practices verification, the aim of identifying the group's predominant sustainability
Recebido

$13 / 01 / 2020$

Aceito

$29 / 04 / 2020$

Publicado

$30 / 04 / 2020$

Acesso aberto

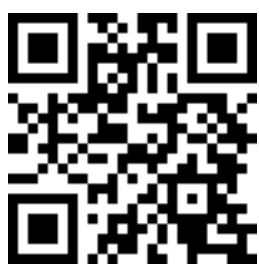

ORCID

(1) 0000-0003-4743-604X Lucelma Maria dos Santos Cunha

D 0000-0003-1165-1813

Maisa de Souza Ribeiro

D 0000-0003-3057-6097 Amaury José Rezende

ISSN 2359-1412/RBGAS-2020-0013/2020/7/15/30/419

Rev. Bras. Gest. Amb. Sustent.

http://revista.ecogestaobrasil.net 
practices, from 2010 to 2017. The data were analyzed longitudinally and in a qualitative way, through an interpretative analysis of actions related to energy and water consumption, water disposal, greenhouse gas emissions and waste management. It was observed the predominance of proactive operational practices, such as energy efficiency projects, measures to reduce water consumption, replace the use of GHG and the management of internal and external waste, as well as the development of actions that seek legal compliance. In general, this study contributes to the identification of environmental actions internal and external to the institution, which can be implemented by the retail sector to reduce costs of environmental impacts caused by its operations and to improve of environmental management.

Keywords: Sustainable practices; Proactivity; Reactivity; Annual reports; Retail.
0000-0001-6704-4196 Mariana Simões Ferraz do Amaral Fregonesi

\section{Introdução}

Agir de forma sustentável é tomar atitudes consistentes com as necessidades presentes e futuras, por meio da gestão da exploração dos recursos, do direcionamento dos investimentos, da orientação do desenvolvimento tecnológico e das mudanças institucionais (Kotzab et al., 2011). 0 gerenciamento da interação da empresa com o meio ambiente ocorre por meio da busca pela mitigação dos impactos das atividades desempenhadas. As ações implementadas de forma espontânea, para melhorar o desempenho ambiental empresarial, seja criando benefícios ou reduzindo os impactos das operações sobre o meio ambiente, é a forma proativa de gerenciamento ambiental, ou seja, voluntária e inovadora, com atitudes voltadas tanto para questões internas quanto para aquelas que se referem à sociedade local. As medidas reativas, como o atendimento mínimo à legislação ou a imposições legais específicas, obrigam as empresas a se adequarem a determinados padrões (Azzone et al., 1997; Aragón-Correa, 1998; GonzálezBenito e González-Benito, 2006).

A postura ambiental da empresa, seja ela reativa ou proativa, não advém somente da necessidade das instituições de se adequarem a novos padrões normativos ou de modismos. As características das empresas tais como tamanho, setor, posição na cadeia de valor e pressões externas também influenciam a postura de gerenciamento ambiental (Roome, 1992; Aragón-Correa, 1998; González-Benito e González-Benito, 2006).

O setor varejista, foco deste estudo, é um distribuidor de produtos acabados e, por isso, recebe grande pressão de stakeholders, visto que estes tendem a culpar as empresas, que colocam os produtos nos canais de distribuição, pelo impacto ecológico da produção (González-Benito e González-Benito, 2006; Jones et al., 2008). Neste contexto, as informações divulgadas pelas empresas têm preponderante importância no estabelecimento de uma comunicação direta com a sociedade e na construção da imagem das empresas, bem como de acordo com diversa pressões, sejam elas de governos, investidores ou shareholders (Calza et al., 2016; Sullivan e Gouldson, 2017; Tang e Demeritt, 2018).

Tang e Demeritt (2018) apontam que 36\% das 168 empresas analisadas por eles mencionaram explicitamente a pressão exercida por investidores, shareholders ou clientes na divulgação voluntária de emissões e na divulgação acima do mínimo exigido compulsoriamente. Mas Sullivan e Gouldson (2017) afirmam que a pressão externa sobre 
empresas de varejo depende dos seus países de operação, da posição de mercado destas empresas e de quem sãos seus principais stakeholders.

Em decorrência de questões operacionais, sejam positivas ou negativas, é desejável e esperado que as empresas divulguem suas práticas como forma de prestar contas à sociedade, especialmente das implicações sociais e ambientais do negócio (Kolk, 2005), como a emissão de carbono (Matsumura et al., 2014). Parte desta prestação de contas está disposta nos Relatórios Anuais de Sustentabilidade, informação pública divulgada voluntariamente pela empresa.

Neste contexto, por meio da leitura e análise interpretativa dos relatórios anuais de um grupo varejista, este estudo buscou responder à seguinte pergunta de pesquisa: quais são as práticas de sustentabilidade predominantes do grupo varejista investigado? Pelo desenvolvimento de uma investigação longitudinal e qualitativa, o objetivo da pesquisa é identificar quais são as ações de gerenciamento ambiental passíveis de aplicação no setor varejista no que se relaciona ao consumo de energia e água, ao descarte de água, à emissão de gases do efeito estufa e à gestão de resíduos. Na gestão do impacto ambiental, o grupo analisado declara que estes quatro temas são considerados materiais na busca por melhores práticas em suas atividades e operações (GPA, 2017).

Buscou-se, especificamente, identificar quais práticas são predominantes no grupo investigado, demonstrando-se a tendência de divulgação destes quesitos, tanto daqueles decorrentes de práticas voluntárias quanto de compulsórias, cenário que pode servir de exemplo para demais empresas, especialmente as do mesmo setor, a exemplo de Jones et al. (2008) e Kotzab et al. (2011).

A justificativa para se analisar as ações de gerenciamento ambiental de uma empresa varejista reside no desejo de conhecer e disseminar práticas proativas e reativas no setor em questão, que possam contribuir para o desenvolvimento sustentável, e identificar o que prevalece entre as iniciativas próprias ou aquelas implementadas por força de lei. Desta forma, há espaço para a investigação/apresentação destas ações, principalmente com o enfoque em outras empresas semelhantes, que podem desenvolver uma curva de aprendizado no que se refere à práticas sustentáveis no setor varejista.

\section{Referencial teórico}

A produção sustentável ou a possibilidade de influenciar comportamentos advém, dentre outros fatores, de uma gestão ambiental responsável, com o uso dos recursos existentes focado nas necessidades futuras, implementada tanto com ações empresariais proativas quanto com o atendimento a legislação específica.

\section{Proatividade nas organizações}

Tang e Demeritt (2018) citam que as empresas se engajam voluntariamente em questões ambientais motivadas pelo ganho financeiro, por fatos relacionados à reputação/pressão social ou pela compulsão regulatória. Ações voluntária são ditas proativas e as empresas proativas implementam a prevenção por meio de padrões pautados pela consciência dos problemas existentes, pela pressão de stakeholders e/ou suas características (Azzone et al., 1997; Aragón-Correa, 1998; Kolk, 2005; GonzálezBenito e González-Benito, 2006; Calza et al., 2016; Valero-Gil et al., 2017; Tang e Demeritt, 2018), além da percepção das vantagens competitivas que podem ser obtidas por meio da adoção de uma postura proativa e consequente melhoria do desempenho ambiental (Aragón-Correa, 1998; Calza et al., 2016; Valero-Gil et al., 2017) e benefícios econômicos na redução de emissões e na eficiência energética (Tang e Demeritt, 2018).

Aragón-Correa (1998), um dos estudos pioneiros nesta temática, relacionou as práticas ambientais mais proativas à busca espontânea pela melhoria da performance ambiental, refletindo a responsabilidade da empresa de forma construtiva e voluntária, 
independente de exigência legal. Para o autor, quanto mais proativa, mais sustentável a empresa tende a ser, devendo apresentar respostas mais tempestivas e apropriadas aos desafios relacionados à exploração do meio ambiente. Para Valero-Gil et al. (2017), mudanças pró meio ambiente refletem modificações realizadas pela empresa em seu ciclo de produção ou em sua estrutura a fim de diminuir o impacto ambiental, a exemplo do controle e prevenção da poluição, diminuição no uso de recursos naturais ou mudanças na operação/procedimentos de gestão.

Na postura proativa a implementação de atitudes sustentáveis ocorre antes da empresa ser requerida, multada ou sofrer qualquer outro tipo de sanção, caso este que se relaciona a ações implementadas de forma reativa. As instituições que praticam medidas reativas tipicamente exercem atitudes end-of-pipe, método tradicional limitado a implementar transformações compulsórias mínimas para o atendimento a alguma regulação, segundo González-Benito e González-Benito (2006). Apesar de criar custos adicionais, a obrigatoriedade de se obedecer a determinadas normas tem efeitos positivos no longo prazo, tanto na esfera econômica quanto na ecológica (Kotzab et al., 2011).

Nesse mix de atitudes proativas e reativas, González-Benito e González-Benito (2006) afirmam que a empresa se torna ambientalmente diferenciada no meio econômico e social quando sua performance ambiental melhora além dos requisitos regulatórios, sendo esta proatividade direcionada tanto para o meio externo quanto para a análise das transformações ambientais realizadas nas operações e no sistema de produção da empresa.

A empresa pode iniciar o seu desenvolvimento sustentável por meio de medidas reativas e se transformar, conforme aprende e desenvolve estratégias mais eficientes e controla os custos envolvidos nas atitudes. Kotzab et al. (2001) apontam que as empresas do setor de varejo poderiam utilizar positivamente a posição mercadológica delas para influenciar a transformação na cadeia de suprimentos e mercado em que elas operam e identificaram, por meio de observação empírica de relatórios ambientais de 92 empresas de varejo, oito categorias relacionadas à sustentabilidade no varejo, a saber: atitude ambiental fundamental, relacionada à conscientização das questões ambientais neste setor, uso de energia, uso de materiais no processo produtivo, de produtos e de embalagens, transporte, consumo e desperdício. Os autores analisaram 34 cadeias de suprimentos e apontaram que o encorajamento para a responsabilidade ambiental e a melhora contínua na cadeia de suprimentos são os itens mais mencionados pelos varejistas. A segunda informação mais divulgada se relaciona às iniciativas ambientais para redução de energia e consumo de recursos nas construções. A terceira e a quarta medidas mais citadas, que englobam tanto varejistas como consumidores, são direcionadas ao manuseio de resíduos e materiais para reciclagem. A quinta medida é a cooperação com outras empresas.

No que se refere às iniciativas ambientais para redução de energia consumida, González-Benito e González-Benito (2006) apontam que elas se referem a práticas operacionais internas, ditas de prevenção, a exemplo da busca pelo uso de energia renovável e aquisição de tecnologias mais limpas. Sullivan e Gouldson (2017) citam que, via de regra, as empresas do setor varejista do Reino Unido esperam retorno financeiro em até três anos, advindos da economia de energia e reduções de emissões de gases de efeito estufa.

O inventário de emissões permite à empresa conhecer o seu histórico de emissão e identificar onde as ações de sustentabilidade podem ser implementadas. Empresas contribuem substancialmente na emissão de GEE (Sullivan e Gouldson, 2017) e Tang e Demeritt (2018) apontam que empresas de capital aberto de alguns países tais como Reino Unido, Noruega, Singapura e Hong Kong já elaboram inventário de emissões compulsoriamente em resposta à pressão governamental; os autores apontam, entretanto, que no Reino Unido, por exemplo, a divulgação de inventário de emissões já era uma 
prática corriqueira das empresas, mesmo antes de sua implementação mandatória, um exemplo de ação proativa. Matsumura et al. (2014) investigaram 500 empresas participantes do índice Standard \& Poor's, de 2006 a 2008, e identificaram que empresas que divulgam suas emissões de carbono tem valor de mercado, em média, 2,3 bilhões de dólares maior do que o aquelas que não divulgam.

Outros fatores que podem determinar a proatividade de uma empresa estão relacionados às características das instituições e uma das mais citadas na literatura relaciona-se ao tamanho da empresa: quanto maior a empresa, por exemplo, maior a disponibilidade de recursos e o nível de proatividade das ações implementadas em prol do meio ambiente, além do impacto positivo em um número maior de clientes (AragónCorrea, 1998; González-Benito e González-Benito, 2006). Aragón-Correa (1998), por meio de questionário respondido por 105 empresas espanholas, atestaram que o tamanho das instituições tem forte implicação na postura proativa ambiental delas, por estas terem mais recursos que as empresas menores. Outra característica que pode influenciar na gestão ambiental e é constantemente discutida na literatura é a internacionalização. Segundo González-Benito e González-Benito (2006), as empresas que se internacionalizam se beneficiam de transferência de conhecimento, o que facilita a adoção de práticas proativas e a rápida imitação de subsidiárias mais avançadas; a posição na cadeia produtiva também determina a proatividade da gestão ambiental, pois quanto mais próximo do cliente final, maior a influência da proatividade, o que se aplica ao varejo.

Dado que todos os stakeholders têm interesses na empresa, eles estão sujeitos aos resultados que a empresa apresenta, devendo estas fornecer informações para que os diversos usuários possam tomar decisões e verificar como as empresas atuam em relação ao meio ambiente (Tinoco e Kraemer, 2011). Assim, assume-se que a informação ambiental é material, pelo menos para aqueles que utilizam os relatórios ambientais (Deegan e Rankin, 1997).

Isto implica, por outro lado, em pressão dos stakeholders pelo melhor resultado da empresa. González-Benito e González-Benito (2006) afirmam que esta pressão pode promover a adoção de ações ambientais proativas que podem afetar a performance da empresa, visto que a sobrevivência da empresa depende da capacidade dela de gerar valor para o stakeholder primário e satisfazer as demandas e expectativas dele, com integridade, respeito, padrões, transparência e accountability. Deegan e Rankin (1997) afirmam que companhias com registros de desempenho ambiental pobre podem encontrar dificuldades em obter os recursos e suportes necessários dos stakeholders investidores para continuar suas operações em uma comunidade que valoriza o meio ambiente limpo, podendo a sociedade "revogar" o contrato social com a empresa.

Neste cenário em que pesquisas consolidadas apontam relação entre as características empresariais e as boas práticas de gestão ambiental, é relevante observar as ações de gerenciamento ambiental e sua divulgação pelas empresas nos diversos setores, inclusive o varejista.

\section{Setor Varejista e os impactos ambientais}

Os produtos finais devem ser analisados em relação à sua sustentabilidade para que os tomadores de decisão se movam em direção a materiais, produtos e empreendimentos mais sustentáveis (Waage et al., 2005). 0 varejo se caracteriza por ser o penúltimo elo na cadeia mercadológica: além de existir uma maior pressão dos clientes sobre os fabricantes de produtos acabados, este setor tem maior proximidade e exerce comunicação direta com os consumidores e fornecedores finais, o que pode ser um fator determinante da proatividade ambiental de uma empresa (González-Benito e GonzálezBenito, 2006).

O varejo, especialmente o de grande porte, é o guardião do desenvolvimento ambiental na cadeia produtiva e as empresas deste setor podem se utilizar desta posição 
para influenciar positivamente a transformação ambiental na cadeia produtiva e nos mercados nos quais elas operam (Jones et al., 2008; Kotzab et al., 2011). Este setor tende a causar menor impacto ao meio ambiente do que o setor industrial, visto que as operações desenvolvidas normalmente não incluem atividades de transformação ou de exploração direta de recursos naturais. No entanto, como está mais ao final da cadeia produtiva, tem sob seu encargo parte dos resíduos do processo produtivo e das embalagens.

González-Benito e González-Benito (2006) afirmam que o setor de atividade econômica é uma variável essencial para o estudo de gerenciamento ambiental dado que cada um tem um potencial poluidor diferente do outro e, por isso, cada um está sujeito a diferentes controles e fiscalizações. 0 varejo tem participação significativa na emissão de carbono (Sullivan e Gouldson, 2017) e as atividades de gerenciamento ambiental no varejo têm, entre seus direcionadores no Brasil, a Política Nacional de Resíduos Sólidos (PNRS), legislação aplicável ao setor, mesmo considerando que o nível de impacto das operações desenvolvidas seja menor do que na indústria, por exemplo.

Kotzab et al. (2011) criaram uma escala para avaliar os elementos ambientais que estão presentes na cadeia de suprimentos do varejo. Uma das instituições analisadas foi o Carrefour, empresa francesa, internacional, de grande porte e com perfil bastante semelhante ao da empresa analisada neste estudo. Os autores declaram que o Carrefour desenvolveu um projeto de comércio justo e que assumiu toda a responsabilidade, desde o produtor até o consumidor, dando prioridade a um diálogo construtivo com os stakeholders. Segundo os autores, em 2008 as ações ambientais do Carrefour se pautaram principalmente na redução da emissão de gases causadores do efeito estufa (GEE), na luta contra a mudança do clima, em investimento em eficiência energética, na eliminação de atividades que criam grande quantidade de resíduos e no aumento da reciclagem dos resíduos materiais.

Jones et al. (2008) abordaram o Retail Futures, documento com algumas perspectivas de como o varejo, no Reino Unido, se parecerá em 2022 e que estabelece uma regra importante para o varejo: olhar primeiro para o consumidor. No estudo são propostos quatro cenários que vão desde o enfraquecimento do grande varejo mediante $o$ crescimento de lojas locais, cooperativas e vendas online, até aquele em que o grande varejo é altamente regulado e domina o cenário por meio do controle da cadeia de suprimentos, principalmente dos produtores e dos fornecedores, e se responsabiliza pela eliminação dos resíduos. No que se refere às implicações para o desenvolvimento sustentável, os autores afirmam que há a necessidade de se gerar produtos mais sustentáveis, de altos valores e baixos custos, a fim de se modificar as percepções dos consumidores.

\section{Metodologia}

\section{Caracterização do sujeito de estudo}

A instituição selecionada para investigação neste estudo foi o Grupo Pão de Açúcar (GPA), nome utilizado em pregão pela Companhia Brasileira de Distribuição (CBD). 0 grupo é uma corporação multi negócio, cuja atividade principal é o comércio varejista, no setor de comércio e distribuição, listada na Brasil, Bolsa e Balcão (B3), no nível 1 de Governança Corporativa, além de ser internacionalizada por meio da negociação de American Depositary Receipt (ADR) de nível III na Bolsa de Valores de Nova York (NYSE) (CBD, 2018).

O GPA passou por importantes transformações nos últimos anos, principalmente no que se refere ao seu controle acionário, antes familiar, que passou a ser exercido, em 2012, pela corporação francesa Casino, um dos líderes mundiais no varejo de alimentos (GPA, 2013). A partir de 2015 e até a atualidade, a empresa passou a ser indiretamente controlada pelo Almacenes Exito S.A., através da Wilkes Participações S.A., e controlada 
final do Casino (CBD, 2015). O GPA cita que em novembro de 2016 passou a negociar a alienação da sua participação na Via Varejo, motivo pelo qual alguns dados para esta holding não são apresentados nos seus Relatórios Anuais de 2016 e 2017 (GPA, 2016). De acordo com Fato Relevante divulgado pelo grupo em 03/11/2016, o intuito da reorganização societária é priorizar o negócio alimentar, principal atividade desenvolvida pela CBD (B3, 2016).

\section{Justificativa para a escolha}

Devido à sua posição na cadeia mercadológica, o setor de varejo fornece esclarecimentos importantes no exame do impacto e influência de diferentes formas de governança nas práticas corporativas (Sullivan e Gouldson, 2017). Além disso, a escolha pela análise das informações deste grupo varejista se deu pela disponibilidade dos dados públicos e por diversos fatores determinantes de práticas ambientais, dos quais três foram destacados: (1) o tamanho da empresa, mensurado pela quantidade de lojas ou de funcionários, por exemplo - o GPA foi considerada em 2017 a maior empregadora privada no Brasil, em sua área de atuação, segundo a Sociedade Brasileira de Varejo e Consumo (SBVC, 2017); tal fato pode determinar a maior disponibilidade de recursos para utilização na gestão ambiental (Aragón-Correa, 1998; González-Benito e González-Benito, 2006); (2) por ser internacionalizada, com negociações na NYSE, a adoção de práticas proativas pode ser facilitada e/ou incentivada, o que inevitavelmente influencia a gestão ambiental da empresa (González-Benito e González-Benito, 2006); e (3) a empresa pertence ao setor de comércio e distribuição, o que a coloca próxima ao consumidor final (Roome, 1992; Aragón-Correa 1998; González-Benito e González-Benito, 2006), sofrendo forte influência da expectativa de stakeholders, o que pode determinar a visibilidade de suas práticas. Estes fatores influenciam a gestão do impacto ambiental e são, assim, preponderantes, neste estudo, para permitir a investigação das ações da empresa, principalmente daquelas proativas, visto que se espera, por determinações legais, que as ações reativas sejam normalmente cumpridas pelas por ela.

\section{Materiais e métodos}

Este estudo caracteriza-se como qualitativo e longitudinal, compreendendo a análise dos Relatórios Anuais do GPA, de 2010 a 2017, divulgados de 2011 a 2018, e foi desenvolvido por meio da análise interpretativa dos dados referentes. Para o recorte deste estudo as variáveis de investigação correspondem aos quesitos ambientais que a empresa apresentou na maioria dos anos analisados e que o próprio grupo considera como materiais (GPA, 2017), sendo eles: consumo de energia, consumo e descarte de água, emissões GEE e iniciativas relacionadas à gestão de resíduos, tanto internos ao grupo quanto coletados na sociedade. A análise foi assim direcionada para permitir o maior grau de comparabilidade possível dentre os anos analisados, a fim de se estabelecer um padrão de consistência da informação para a interpretação. Severino (2000) explica que a análise interpretativa se refere à compreensão objetiva e interpretação da mensagem comunicada, o que significa tomar um posicionamento próprio a respeito do que se estuda e ir além do que as palavras buscam dizer, mas com o risco de se incorrer em subjetividades.

O GPA elabora Relatórios Anuais/de Sustentabilidade desde 1999 e os disponibiliza para download em seu website institucional. Segundo González-Benito e González-Benito (2006), a própria elaboração periódica de relatórios ambientais pode ser caracterizada como uma prática proativa em relação ao meio ambiente, pois é fruto de uma ação voluntária da empresa. As práticas de comunicação, segundo os autores, são utilizadas como forma de se manter a conexão da empresa com o ambiente econômico e social e podem, por consequência, ser utilizadas com objetivos propagandísticos. De 2008 a 2013 os citados relatórios foram elaborados de acordo com as diretrizes GRI e, em 2014, 
o grupo passou a adotar a metodologia utilizada internacionalmente pelo Grupo Casino, a United Nations Global Compact Principles. A leitura analítica dos Relatórios Anuais foi realizada, seguida da compilação dos dados em Excel, de forma que possibilitasse posterior análise descritiva das ações de gerenciamento ambiental da instituição selecionada, conforme seção seguinte.

\section{Resultados e discussão}

A análise dos Relatórios Anuais do GPA permitiu verificar as práticas de sustentabilidade predominantes do grupo, ano a ano, referentes à evolução do consumo de energia, do consumo e descarte de água, das emissões de GEE e dos resíduos coletados, tanto interna quanto externamente ao grupo. Os resultados referentes a estes itens foram apresentados em valores absolutos, ou seja, da forma que foram divulgados (lado esquerdo das figuras apresentadas), e divididos pelo número de unidades logísticas (lado direito), conforme distribuição na Tabela 1.

Tabela 1. Evolução no tamanho do grupo (unidades).

\begin{tabular}{|c|c|c|c|c|c|c|c|c|}
\hline Ano & 2010 & 2011 & 2012 & 2013 & 2014 & 2015 & 2016 & 2017 \\
\hline $\begin{array}{l}\text { Presença } \\
\text { estados }\end{array}$ & 20 & 20 & 19 & 19 & 19 & 20 & 16 & 18 \\
\hline $\begin{array}{l}\text { Número de } \\
\text { colaboradores }\end{array}$ & 144.914 & 149.070 & 158.509 & 169.959 & 173.906 & 160.000 & 100.605 & 100.288 \\
\hline Variação & - & $3 \%$ & $6 \%$ & $7 \%$ & $2 \%$ & $-8 \%$ & $-37 \%$ & $0 \%$ \\
\hline Número de lojas & 1647 & 1882 & 1804 & 1999 & 2141 & 2181 & 1135 & 1081 \\
\hline Variação & - & $14 \%$ & $-4 \%$ & $11 \%$ & $7 \%$ & $2 \%$ & $-48 \%$ & $-5 \%$ \\
\hline
\end{tabular}

Os relatórios anuais do GPA apresentam detalhamento ao longo do período analisado. Contudo, alguns dados são reapresentados em anos posteriores, com valores divergentes, mas nem sempre com justificativa para os ajustes; neste caso, optou-se pela análise das informações mais recentes, no pressuposto de que ajustes são realizados para melhor representar a realidade. Em adição, provavelmente devido à mudança de metodologia de elaboração dos citados relatórios, ocorrida em 2014, houve alteração na forma de apresentação de alguns dados, comprometendo a comparabilidade.

A fim de demonstrar o tamanho do grupo analisado, a Tabela 1 apresenta a participação dele nos Estados brasileiros, além da presença do grupo no Distrito Federal em todos os anos analisados, o número total de colaboradores e o número de lojas, bem como a variação destes dois últimos quesitos, relacionando o respectivo valor atual com o do ano anterior.

Comparando a participação do grupo nos Estados brasileiros, observa-se homogeneidade, à exceção de 2016 e 2017, quando a participação do GPA no território nacional decaiu expressivamente: além do Distrito Federal, o grupo estava presente em 20 estados em 2015, 16 estados em 2016 e 18 estados em 2017. 0 número de colaboradores decaiu a partir de 2014, especialmente de 2015 para 2016, uma redução de $37 \%$. Quanto à variação no número de lojas, a Tabela 1 demonstra que de 2015 para 2016 houve queda de $48 \%$ no número de unidades, maior variação identificada no período para este quesito; o número de lojas engloba a abertura e o fechamento de unidades e a reforma e revitalização de algumas construções, incluindo lojas, drogarias e postos de combustíveis. 
Conforme a Tabela 1, as variações negativas nos três quesitos apresentados são mais intensas de 2015 para 2016 e isto se deve, provavelmente, à reorganização societária do grupo: o GPA passou a negociar, em 2016, a alienação da participação em uma de suas controladas, a Via Varejo, motivo pelo qual as informações referentes às atividades desta empresa não foram reportadas nos relatórios de 2016 e 2017, sendo ela considerada, para os efeitos do Relatório Anual do grupo para o período mencionado, uma "operação descontinuada" (GPA, 2016, p. 13).

\section{Consumo de energia}

Uma das dificuldades encontradas nos relatórios anuais do GPA, principalmente sob o modelo GRI, foi comparar os totais de energia gastos, visto que o grupo apresentou estes dados em diversas medidas diferentes ao longo dos anos, como MWh, KWh, J e GJ. Em alguns anos, mais de uma unidade de medida foi utilizada, sem promover, entretanto, a comparabilidade, que obriga o usuário da informação a converter os valores apresentados para uma única unidade, podendo incorrer em erros de análise. Neste estudo, os valores apresentado foram convertidos e padronizados para MWh, que é predominante na divulgação.

Conforme os relatórios anuais analisados, a soma do total e energia consumida pelo grupo no período analisado foi de 10.130.421 MWh. Conforme a distribuição apresentada à esquerda da Figura 1, o maior consumo ocorreu em 2012, 2013 e 2014, com queda no consumo absoluto após este triênio, período em que também se observa redução expressiva na quantidade de funcionários e de lojas. Aproximadamente 4.960.332 MWh (49\%) da energia consumida adveio de fontes renováveis, tipo de energia predominante no montante que pôde ser identificado, tal como hidrelétricas (divulgado de 2010 a 2012) e energia verde (presente para todos os anos analisados), com consumo crescente ao longo dos anos; e aproximadamente 753.204 MWh (7\%) decorreu de fontes não renováveis, como o gás liquefeito de petróleo (GLP) (apresentado de 2012 a 2017) e o gás natural (divulgado para todos os anos analisados). De 2012 a 2017, 44\% da energia consumida pelo grupo não pôde ser elencada como de fonte renovável ou não renovável.

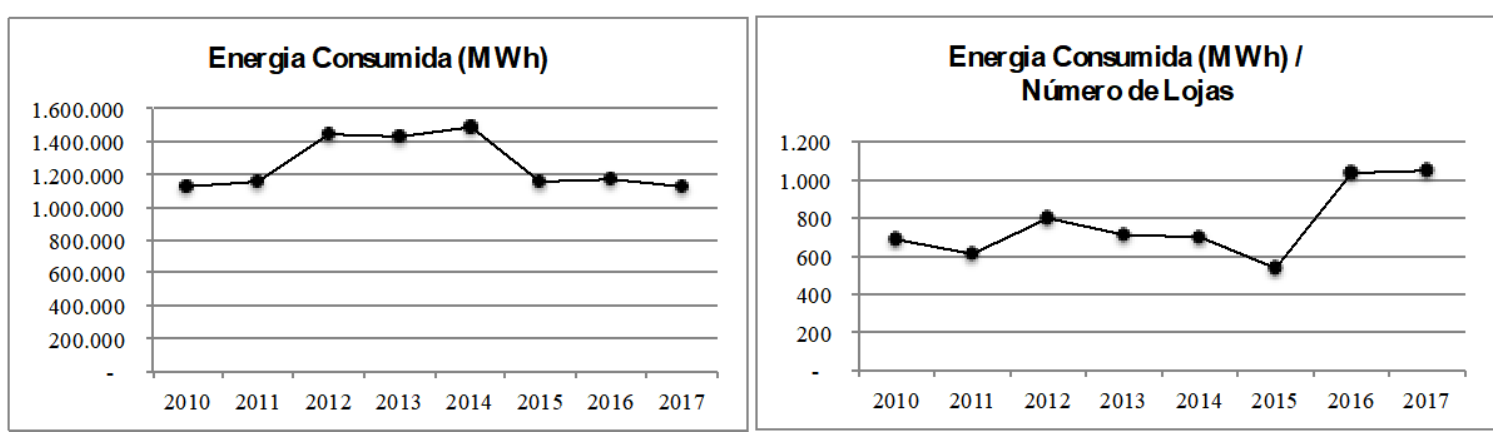

Figura 1. Total da energia consumida (MWh).

Quando observado o total de energia consumido em relação ao número de lojas do grupo, a imagem à direita da Figura 1 demonstra que 2015 apresenta a menor relação estabelecida e isso se deve ao maior número de lojas apresentado ao longo dos períodos analisados. Adicionalmente, apesar da queda no número de unidades de lojas em 2016 e 2017, elevou-se a relação de consumo de energia por loja. O GPA divulgou o total de consumo de óleo, mas não especificou o seu tipo, nem a quantidade referente à energia consumida por meio deste item, o consumo de energia originada de fonte mista, para a 
qual não há identificação de sua composição, e uso de gasolina para carros. Estes valores não ofereciam comparabilidade dentre os anos analisados e por isso não foram especificados neste estudo.

Nas 92 empresas de comércio varejista analisadas por Kotzab et al. (2011), iniciativas ambientais para a redução do uso de energia e consumo de recursos nas construções foram a segunda informação mais frequentemente divulgada nos relatórios ambientais das empresas analisadas. O GPA também implanta ações deste tipo, declarando se dedicar ao desenvolvimento de projetos de eficiência energética e energias renováveis, como a automação do sistema de ar-condicionado, a preferência pela iluminação natural com o uso de zenitais e a troca do tipo de lâmpada utilizada nas lojas e centros de distribuição, priorizando a utilização de lâmpadas led ou outras lâmpadas mais eficientes; o GPA afirma ter implantado sistemas de ar-condicionado com termo acumulação, que armazena água gelada para utilização na refrigeração das lojas em períodos nos quais a tarifa de energia elétrica é mais cara, a automação e colocação de portas nos equipamentos de frio alimentar (freezer) para reduzir as perdas térmicas nas lojas e o uso de geradores nos momentos de pico de energia, dentre outros.

Estes são exemplos de ações pró meio ambiente por meio da mudança de estrutura (Valero-Gil et al., 2017). Em 2017, o grupo destaca que melhorias deste tipo tem gerado uma redução média no consumo de energia na ordem de $25 \%$ em 487 unidades de algumas de suas lojas e que o seu programa de eficiência energética gera uma economia de 124 mil MWh, o que equivale ao consumo residencial de uma cidade como Atibaia, Botucatu ou Barretos (GPA, 2017). Adicionalmente, o grupo declara, em 2017, ter instalado a maior usina solar urbana no Brasil, em Goiânia, o que permitirá economizar $40 \%$ da energia elétrica que seria consumida na loja e evitar a emissão de, aproximadamente, 3 mil toneladas de $\mathrm{CO}_{2}$, o que corresponde a uma economia de $\mathrm{R} \$ 2,6$ milhões ao longo de 25 anos (GPA, 2017).

Como medidas de economia no consumo de energia, a empresa atende ao que González-Benito e González-Benito (2006) chamaram de práticas operacionais internas. Conforme os exemplos elencados, ao mesmo tempo que busca diminuir o consumo de energia, que tem como consequência direta a redução do custo envolvido/ganho econômico (Tang e Demeritt, 2018), as citadas ações do grupo podem culminar na diminuição do impacto ambiental causado (Valero-Gil et al., 2017), principalmente daquele advindo do uso de fonte não renovável de energia e da emissão de GEE.

\section{Consumo e descarte de água}

O consumo total de água no período analisado foi de 25.219 .575 metros cúbicos $\left(\mathrm{m}^{3}\right)$ e a imagem apresentada à esquerda na Figura 2 demonstra a distribuição deste consumo.
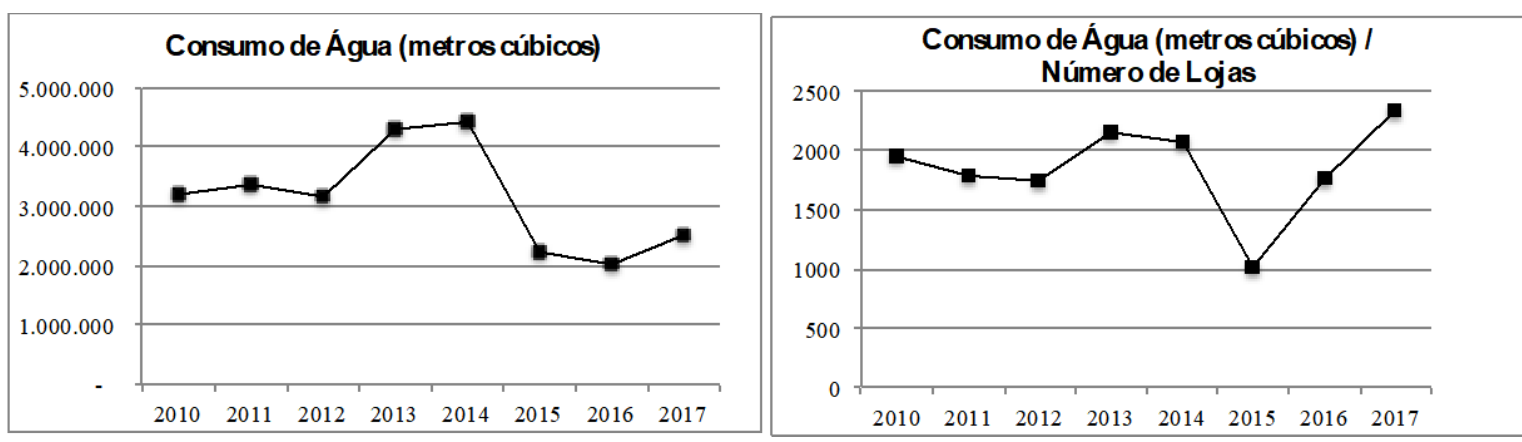

Figura 2. Consumo de água $\left(\mathrm{m}^{3}\right)$. 
0 ano de maior consumo de água foi 2014 e foi possível identificar que praticamente toda a água utilizada pelo grupo foi proveniente do fornecimento municipal. A imagem à direita da Figura 2 demonstra que a menor relação de consumo de água por número de lojas ocorreu em 2015, ano de maior número de lojas apresentado ao longo dos períodos analisados, com subsequente aumento na relação para 2016 e 2017 apesar da queda no número de lojas do grupo.

O grupo implementou, de 2010 a 2013, a título de ações de sustentabilidade, a captura de água da superfície, de água subterrânea, de água da chuva e de água reciclada que totalizaram $246.950 \mathrm{~m}^{3}$ de água captada, um valor inferior a $1 \%$ do total de água consumida no período, mas que representava uma iniciativa da empresa para a economia deste recurso. Entretanto, de 2014 em diante a empresa deixou de divulgar informações sobre este quesito. Ademais, o grupo declara constantemente que implementa ações para reduzir o consumo de água, citando como exemplos a instalação de redutores de vazão nas torneiras das lojas para maximizar a eficiência no uso desse recurso, bem como implementação de sistemas de monitoramento diário do consumo das lojas, visando a rápida detecção de vazamentos, exemplos de ações operacionais do grupo que demonstram práticas proativas perante o meio ambiente.

No que ser refere à água descartada pela organização, há divulgação somente para o período de 2010 a 2013, no total de 14.740 .233 m³$^{3}$, e a imagem à esquerda da Figura 3 demonstra como ocorreu este descarte.
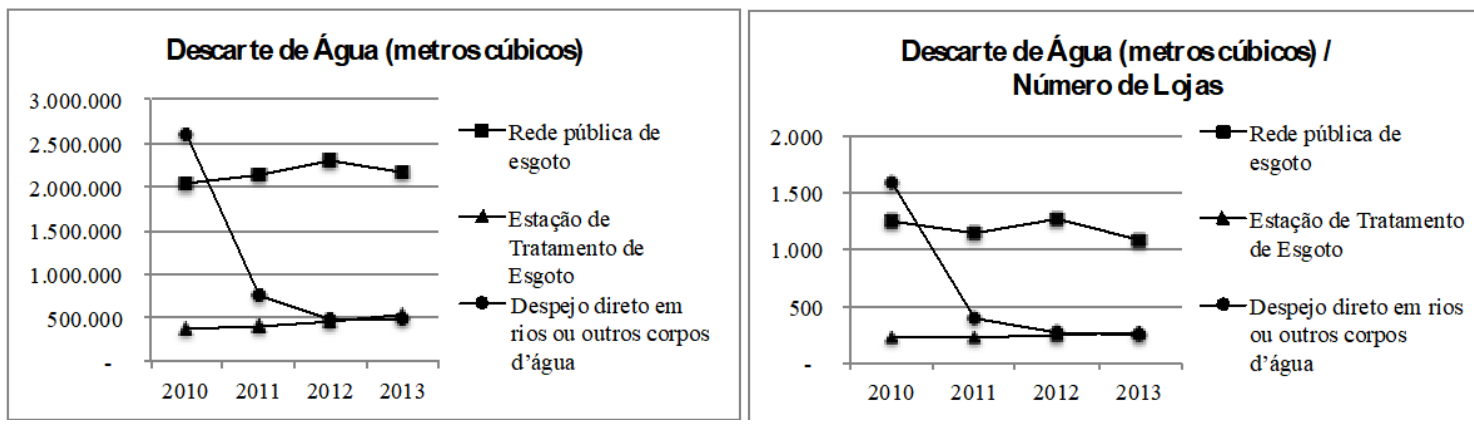

Figura 3. Descarte de água $\left(\mathrm{m}^{3}\right)$.

A aproximadamente $8.642 .286 \mathrm{~m}^{3}$ (59\%) da água descartada de 2010 a 2013 foi escoado pela rede de esgoto da companhia de abastecimento, $4.335 .835 \mathrm{~m}^{3}(29 \%)$ foi despejado diretamente em rios ou outros corpos d'água e $1.762 .112 \mathrm{~m}^{3}(12 \%)$ foi tratado por estações de tratamento de esgoto. A imagem à direita da Figura 3 demonstra o descarte de água em relação ao número de lojas e apresenta um movimento semelhante ao já comentado. Ressalta-se que o grupo divulgou este tipo de dado somente até 2013, quando o modelo GRI era adotado.

Como exemplo de ações sustentáveis perante o meio ambiente, a empresa declara, a fim de diminuir o descarte de água por suas lojas e centros de distribuição, que adota a utilização de água proveniente de tratamento de esgoto, o reuso da água da torre de arcondicionado, a captação de chuva para utilização nos vasos sanitários e a utilização de sistemas de reuso da água para lavagem de veículos pesados. Entretanto, o lançamento de rejeitos em rios ou outros corpos d'água pode ser considerado um ato infrator da empresa e a legislação estadual discorre sobre o tema, a exemplo do Estado de São Paulo (Decreto n. 8.468, 1976). Assim, mesmo com a diminuição do montante despejado diretamente em rios ou corpos d'água, fato que evidencia que a empresa procurou sanar o problema 
relacionado ao esgotamento sanitário, esta prática, dependendo do atendimento à legislação vigente, pode não ser classificada como uma ação operacional sustentável do grupo no período analisado.

Observa-se que as práticas mencionadas demonstram esforços direcionados para otimização do recurso água, fazendo uso do desenvolvimento de novas tecnologias, o que pode ter resultado em redução de custos com esse item, bem como de impactos ambientais. Todavia, tal empenho ainda não foi suficiente para evitar o uso de recursos naturais para despejo dos resíduos do processo produtivo.

\section{Emissões de gases causadores do efeito estufa (GEE)}

O GPA elaborou, em todo o período analisado, inventário de emissão de carbono. De 2010 a 2012 o grupo utilizou o Greenhouse Gas Protocol - GHG Protocol - declarando-se a pioneira no setor varejista a implementar tal ação, em 2010; em 2013 e 2014 utilizou o protocolo de Quioto e de Montreal; e de 2015 a 2017 não informou qual era a metodologia utilizada para o inventário de emissões - diferentes tipos de informação, agregadas e divulgadas de formas distintas, podem complicar a comparação (Tang e Demeritt, 2018). 0 inventário de carbono do GPA é demonstrado na Figura 4.
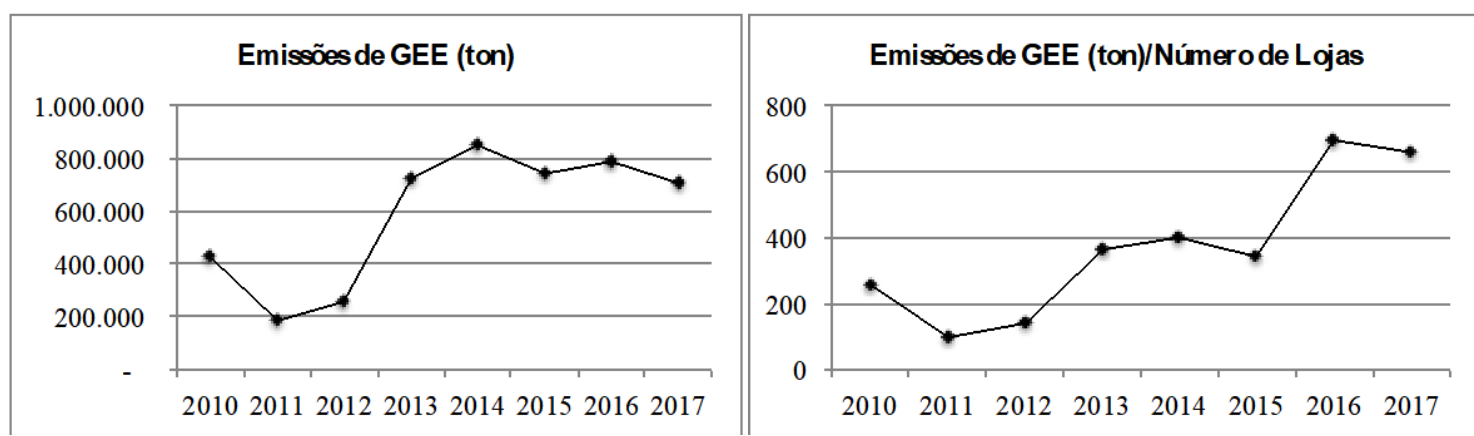

Figura 4. Emissões de GEE (toneladas de $\mathrm{CO}_{2}$ ).

A empresa divulgou emissões de aproximadamente 4.676.557 toneladas de $\mathrm{CO}_{2}$ durante todo o período verificado. Deste total: (1) 866.488 toneladas (19\%) são relacionadas ao GHG Protocol, de 2010 a 2012 - i) Escopo 1: emissões diretas de GEE, provenientes de fontes estacionárias e móveis, pertencentes à empresa ou controladas por ela, como caldeiras e veículos; ii) Escopo 2: emissões indiretas de GEE, provenientes do consumo de energia; e iii) Escopo 3: todas as outras emissões indiretas, consequentes de atividades da empresa, mas que ocorrem em fontes que não pertencem ou não são controladas pela Companhia, como viagens de aeronaves, frota terceirizada, obras de construção civil; (2) 745.383 toneladas (16\%) são de emissões relacionadas ao Protocolo de Montreal e 829.178 toneladas (18\%) são de emissões relacionadas ao Protocolo de Quioto, ambos em 2013 e 2014 - o grupo explica que a variação expressiva de 2012 para 2013 decorre da inclusão no cálculo do carbono emitido do frete terceirizado da Via Varejo (GPA, 2013); e (3) 2.235.508 toneladas (48\%) não tiveram a metodologia identificada pelo grupo e se referem a 2015, 2016 e 2017.

A imagem à esquerda da Figura 4 demonstra que em 2011 o grupo apresentou o menor nível de emissão de GEE - diminuição na emissão de GEE, segundo Tang e Demeritt (2018), pode ser considerada uma boa proxy para demonstrar a eficiência geral da empresa; em 2014, entretanto, o grupo apresentou o maior nível de emissão de GEE. A 
imagem à direita na Figura 4 demonstra o total de emissões considerando o número total de lojas do grupo, permitindo inferir que a emissão de GEE do grupo foi, de forma geral, crescente ao longo do período analisado. Para Matsumura et al. (2014), para cada mil toneladas métricas adicionais que a empresa emite de carbono, o valor da firma diminui, na média, em 212.000 dólares.

Observa-se que o esforço de redução das emissões de 2010 para 2011, foi significativo. Por outro lado, o aumento de emissões pode ser associado tanto a novas emissões quanto ao aumento na capacidade de mensurar a poluição. Durante os anos apresentados a empresa utilizou diversas metodologias para a mensuração de suas emissões, o que pode justificar as variações expressivas verificadas na Figura 4.

Embora Tang e Demeritt (2018) afirmem que há evidência limitada de que a elaboração de relatórios contribua para a diminuição das emissões, deve-se ressaltar que o inventário das emissões de GEE pode ser útil no processo de gestão da organização, como referência de consumos que precisam ser reduzidos e substituições por tecnologias mais avançadas e ecologicamente corretas que devem ser avaliadas.

Outro item constantemente citado pelo grupo é a emissão de R22, um poluente que destrói a camada de ozônio: ele se constitui em uma variação de gás refrigerante utilizado em câmaras frigoríficas, ar-condicionado, geladeiras e freezers. Para o período investigado, o grupo emitiu 1.637 toneladas de gases refrigerantes, sendo eles: R12, R141B, R124, R4010A, R404A, R134A, R22 e outros fluídos não identificados; deste total, 1.552, aproximadamente 95\%, são gases R22. A distribuição da utilização do R22 está descrita na Figura 5.

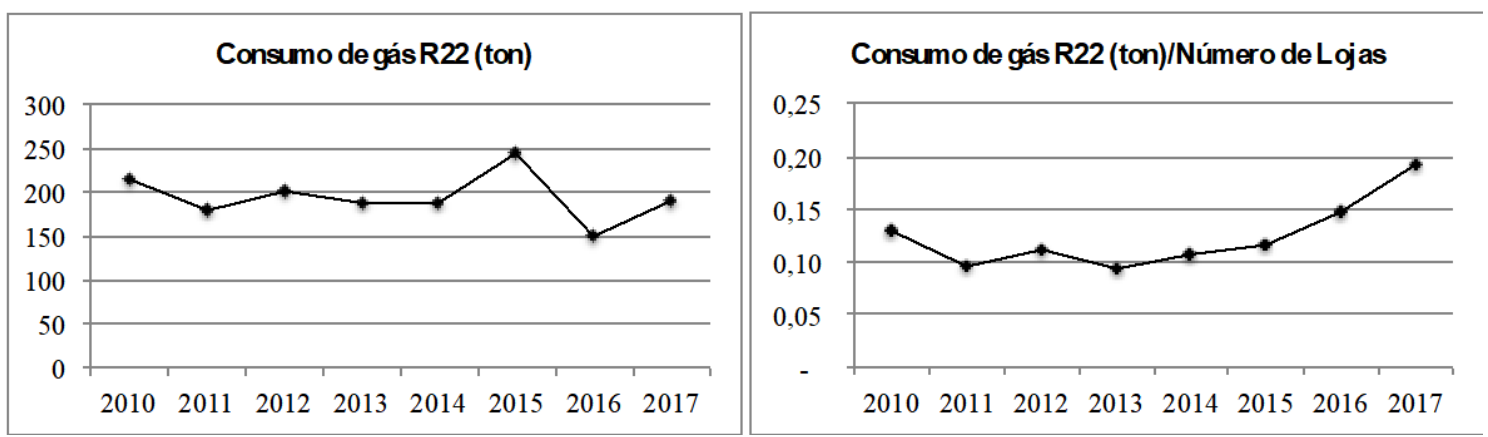

Figura 5. Consumo de gás R22 (t).

A imagem à esquerda da Figura 5 demonstra que de 2015 para 2016 houve decréscimo no total e R22 emitido pelo grupo; entretanto, quando padronizado pelo número de lojas, conforme a imagem à direita da Figura 5, de forma geral o consumo de R22 foi crescente ao longo do período analisado, demonstrando que a substituição do gás R22 por um equivalente menos destrutivo tem sido lenta.

Segundo o Relatório Anual de 2013 (GPA, 2013), o consumo de 186,6 toneladas do gás R22 é análogo à emissão de 20,53 toneladas equivalentes de clorofluorcarbono. A empresa explica que o gás R22 é o mais utilizado pelo GPA, mas declara constantemente que busca reduzir as emissões de GEE, ressaltando que implementa ações para a substituição da utilização de gases refrigerantes mais nocivos e destruidores da camada de ozônio, a exemplo dos hidrofluorocarbonetos (HFCs). A respeito dos demais gases refrigerantes utilizados pelo grupo, cabe ressaltar o crescente uso do R404A: a análise dos relatórios permite identificar que a partir de 2014 o gás R404 foi utilizado em escala 
crescente, partindo de 2,52 toneladas em 2014 para 8,78 em 2017. 0 R404 é um gás refrigerante que causa menor interferência na camada de ozônio, não é inflamável, é mais seguro e mais eficiente quanto ao consumo de energia (GPA, 2017). Segundo GonzálezBenito e González-Benito (2006), a empresa somente demonstra uma prática operacional proativa quando continuamente realiza a substituição de materiais poluentes ou perigosos.

No que se refere aos impactos ambientais referentes à logística, o GPA implementa o que Aragón-Correa (1998) chamou de proatividade ambiental, com a implementação voluntária de práticas e iniciativas que objetivam melhorar a performance ambiental e, conforme Valero-Gil et al. (2017), controlar a poluição. 0 grupo instituiu o programa Backhaul e o divulgou de 2010 a 2013, ou seja, conforme divulgação do Relatório Anual no modelo GRI. 0 sistema foi lançado em 2006 para que o GPA reduzisse a emissão de $\mathrm{CO}_{2} \mathrm{em}$ suas operações, integrando a cadeia de suprimentos à cadeia produtiva: esta é uma estratégia de logística que otimiza o fluxo de viagens entre as lojas e centros de distribuição, dado que os caminhões entregam as encomendas e retornam com artigos de outro fornecedor, ao invés de retornarem vazios. Iniciativas ambientais em colaboração com outras empresas é uma atividade específica da cadeia de suplementos relacionada à atitude ambiental fundamental no varejo, uma das categorias de varejo sustentável apontadas por Kotzab et al. (2011), e demonstram a aquisição de uma visão essencial do varejo em relação às questões ambientais e à cooperação com parceiros.

o Backhaul gera receitas, reduz custos com transporte, aumenta ganhos na produtividade e diminui a quantidade de quilômetros rodados e da emissão de $\mathrm{CO}_{2}$, principal ponto do projeto. À exceção de 2011, no qual os veículos da empresa emitiram aproximadamente 1,05 toneladas de $\mathrm{CO}_{2}$ para cada mil quilômetros rodados, a análise demonstrou que a frota do GPA emitiu uma média de 0,77 toneladas de $\mathrm{CO}_{2}$ para cada mil quilômetros rodados ao ano.

Em outra ação, em 2016 o grupo declara que passou a utilizar carretas tipo rodotrem para o transporte de produtos entre suas lojas e centros de distribuição; este tipo de veículo é tracionado por um cavalo mecânico com motor híbrido, movido a gás natural - menos poluente - e tem capacidade de carga 50\% maior do que as carretas convencionais, permitindo ao grupo economizar na quantidade de viagens realizadas e reduzir em $70 \%$ as emissões de $\mathrm{CO}_{2}$ nas citadas operações de transporte (GPA, 2016).

Em 2017 o grupo declarou que estava implementando a ampliação do número de caminhões double-deck - dois andares - como parte da estratégia para aumento da produtividade logística; neste ano o grupo contava com cinco unidades e uma meta de aumento para 18 unidades em 2018; segundo o grupo, a utilização deste tipo de caminhão corresponde ao transporte de 1,5 volume da carreta convencional, o que permite, dentre outros fatores, redução de mais de $33 \%$ na emissão do $\mathrm{CO}_{2}$ emitido durante o percurso (GPA, 2017).

Em comparação ao estudo realizado por Kotzab et al. (2011), tanto o GPA quanto o Carrefour tomaram medidas para reduzir emissões: o Carrefour atingiu a meta de transportar $45 \%$ das mercadorias importadas por meio de transporte fluvial e ferroviário, evitando assim a emissão de 286 toneladas de $\mathrm{CO}_{2}$, enquanto o GPA implementou o programa Backhaul, economizando no número de viagens realizadas, e a utilização de caminhões rodotrem e double-deck. Ademais, González-Benito e González-Benito (2006) citam, como práticas operacionais proativas, a escolha por um método de transporte mais limpo, bem como projetos com foco na redução do consumo de recursos e geração de resíduos durante a produção e distribuição, o que vai ao encontro das práticas adotadas pela empresa analisada.

Em síntese, apesar do aumento na emissão de GEE e na utilização de gases R22, em relação ao número de lojas, o GPA tem buscado, conforme os citados exemplos, medidas para a diminuição das suas emissões. A redução nas emissões ocasionam economia de 
recursos financeiros (Tang e Demeritt, 2018) e diminuem o impacto ambiental causado pelas atividades do grupo, ações de sustentabilidade que, se permeadas no longo prazo, são consideráveis para o controle das mudanças climáticas, principalmente se adotados em larga escala por empresas de qualquer setor.

\section{Gestão de resíduos}

A gestão dos resíduos implementada pelo GPA pode ser dividida em duas vertentes: resíduos resultantes da própria operação da empresa, ou seja, internos, e resíduos advindos de clientes, externos, conforme a Figura 6.

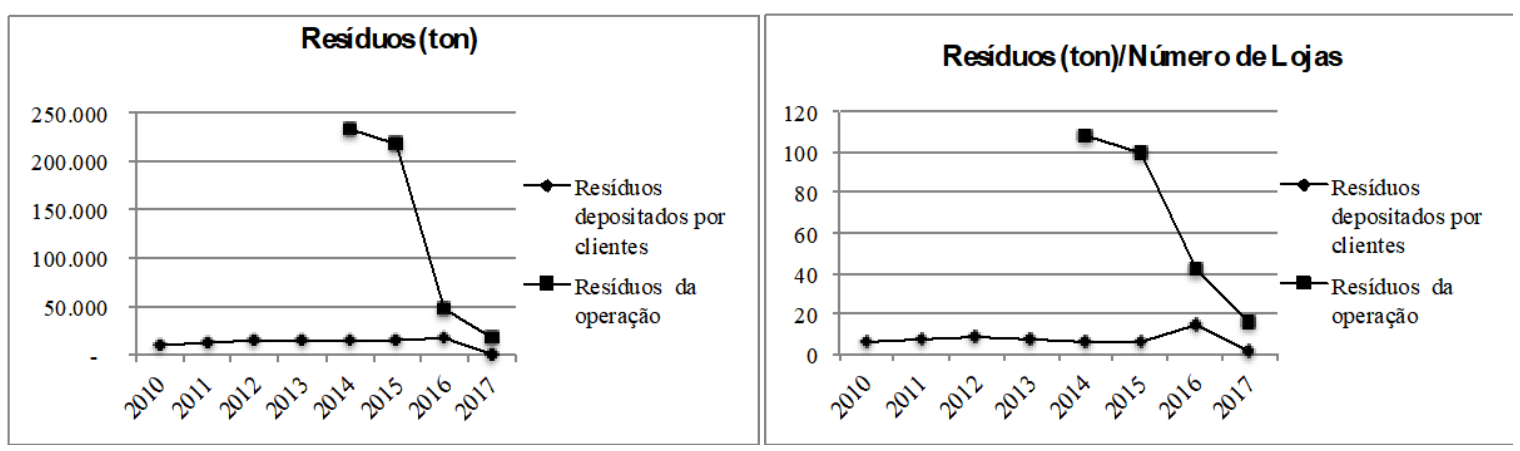

Figura 1. Resíduos (t).

O GPA não divulgou números para todos os anos, mas foi possível identificar que, de 2014 a 2017, o grupo coletou mais de 513.527 toneladas de resíduos relativos às suas operações e os destinou à reciclagem, à logística reversa e à compostagem, no caso dos resíduos orgânicos. 0 manuseio de rejeitos e materiais recicláveis faz parte das oito relacionadas à sustentabilidade no varejo (Kotzab et al., 2011). Como a coleta seletiva só foi divulgada após 2010, ano de promulgação da PNRS, subtende-se que este tipo de coleta ocorre primariamente em resposta à adequação da empresa à PNRS e seria, portanto, o atendimento à obrigatoriedade de cumprir "metas de redução, reutilização, coleta seletiva e reciclagem, entre outras, com vistas a reduzir a quantidade de rejeitos encaminhados para disposição final ambientalmente adequada", conforme dispõe a PNRS (Lei n. 12.305, 2010).

Dos resíduos advindos da operação ressalta-se a divulgação somente a partir de 2014, quando os Relatórios de Anuais do GPA passaram adotar a metodologia do grupo Casino, a United Nations Global Compact Principle. Segundo os Relatórios Anuais analisados, houve destinação correta de papéis, papelão, plástico, resíduos orgânicos, óleo de cozinha usado, cartuchos para impressoras profissionais, sucatas e metais, resíduos eletroeletrônicos, resíduos reciclados, rejeitos, outros reaproveitamentos, resíduos industriais banais (RIB) mistos - o grupo não explica do que se tratam estes últimos quatro itens - e lâmpadas, consideradas resíduos perigosos. Na Figura 6, o valor de 2015 é mais alto especialmente pela destinação de RIB, que compreende aproximadamente 164.971 toneladas de resíduos para este ano (71\% do total referente ao ano). Em 2016, a destinação de rejeitos compreende 95.410 toneladas do total dos resíduos destinados no ano, aproximadamente $44 \%$.

0 projeto de gestão de resíduos externos ao grupo é uma das forma de interação do varejo com a sociedade (Jones et al., 2008) e foi iniciado pelo GPA em 2001, compreendendo, em grande parte, a disponibilização de estações de reciclagem nos 
estacionamentos de diversas lojas do grupo. Os materiais recolhidos compreendem diversas modalidades, a exemplo de papel, papelão, plástico, sucatas e metais, alumínio, vidro, celulares, pilhas, baterias, lixo eletrônico, óleo de cozinha usado, outros resíduos de clientes, não explanado pelo grupo, e lâmpadas. Foram coletadas, de 2010 a 2017, mais de 98.655 toneladas de resíduos secos, com maior coleta de plástico, papel e alumínio, materiais que são enviados a cooperativas e transformados em novas embalagens.

Com esta medida a empresa oferece alternativas para os clientes descartarem materiais recicláveis em postos de entrega voluntária. Esta ação, além de ajudar a preservar o meio ambiente, gera emprego e renda para as cooperativas de coleta e reciclagem que participam do programa - o material arrecadado é doado para tais cooperativas, uma vertente social da PNRS. Parte deste material entra em um programa de economia circular, por meio de sua reutilização na composição de novos produtos, reduzindo o impacto ambiental das operações do grupo (GPA, 2017), visto que a substituição de materiais permite a geração mais consciente de produtos (González-Benito e González-Benito, 2006).

Vale ressaltar que a quantidade coletada de resíduos externos é um fator que foge ao controle do GPA, pois este oferece as condições para o descarte correto de resíduos, cabendo à população aderir aos programas apresentados pelo grupo. Aragón-Correa (1998) considera a reciclagem de resíduos um método tradicional de correção, ou seja, geralmente sujeito à regulação pública. A implantação das citadas estações de reciclagem faz parte da PNRS, mas foi implementa pela empresa a partir de 2001, quando a Lei Federal $n^{0} 12.305$, de 2010, ainda estava em discussão no Congresso, ou seja, não era mandatória. Neste cenário, a coleta de resíduos externos pode ser classificada, de acordo com o autor, como uma iniciativa de proatividade estratégia, visto que ao invés de agir reativamente, a empresa buscou iniciar mudanças políticas antes que elas fossem demandadas. No que se refere à coleta de óleo de cozinha, esta também pode ser considerada proativa, visto que não há regulação específica para este tipo de reciclagem - a PNRS legisla sobre resíduos tais como os óleos lubrificantes (Lei n. 12.305, 2010).

Dentre os projetos relacionados à gestão de resíduos externos pode-se destacar:

(1) "Caixa Verde": divulgado de 2008 a 2014, o programa consiste em um sistema de coleta seletiva pré-consumo e destinação correta de resíduos, no qual a instituição dispõe caixas coletoras no interior das lojas para que os consumidores descartem as embalagens que preferirem não levar para casa. A iniciativa se expandiu rapidamente tendo coletado mais de 5,7 milhões de embalagens desde o início do programa. Além de ser uma atitude inovadora e proativa da empresa, por implementar a responsabilidade compartilhada pelo ciclo de vida dos produtos antes mesmo de ser requerida por força legal, o que Aragón-Correa (1998) chama de melhorias voluntárias preventivas, a empresa se antecipa à legislação de resíduos sólidos. As embalagens coletadas são doadas para cooperativas de reciclagem parceiras do GPA, atitude pela qual a empresa reforça também a sua proatividade social, por contribuir para a geração de emprego e renda para os entes envolvidos nestas associações;

(2) descarte correto de medicamentos e objetos cortantes: este programa compreende a destinação adequada de medicamentos fora de uso ou vencidos e produtos ou embalagens cortantes, tais como agulhas e ampolas; de 2011 a 2014, período no qual houve divulgação de dados para este programa, mais de 16 toneladas deste tipo de material já foi coletado pelo GPA. Observado o ano de seu início, este programa é prioritariamente reativo, pois ele surge em resposta à PNRS, que apregoa, além da responsabilidade compartilhada pelo ciclo de vida dos produtos, a destinação ambientalmente adequada de resíduos, com a disponibilização de locais de coleta e implantação de logística reversa para resíduos perigosos (Lei no 12.305/2010); 
(3) Coleta de celulares, pilhas e baterias: implementada em 2010 e em continuidade, compreende a logística reversa de aparelhos celular e materiais relacionados, como pilhas, baterias e demais acessórios. Desde o início do programa, o GPA arrecadou mais de 120 toneladas destes materiais, contribuindo para inibir o descarte inadequado desses itens tóxicos que podem contaminar o solo e lençois freáticos. Por meio desta ação a empresa emprega reativamente esforços para maximizar a logística reversa de resíduos perigosos, visto que a Lei n. 12.305 é enfática ao determinar que tanto fabricantes, importadores, distribuidores ou comerciantes devem se responsabilizar pelo retorno de pilhas e baterias, dentre outros produtos, após o material ter sido utilizado pelo consumidor (Lei no 12.305/2010); e

(4) Coleta de lixo eletrônico: desde 2011, em parceria com a Associação Brasileira de Empresas de Limpeza Pública e Resíduos Especiais (ABRELPE), a empresa iniciou a coleta de lixo eletrônico, por meio da qual se torna possível descartar impressoras, televisores, videocassetes, computadores, aparelhos de DVD e microondas, entre outros. Com esta medida, o GPA coletou mais de 275 toneladas destes produtos desde o início do programa. Essa ação é uma das premissas da PNRS e se refere à logística reversa destes equipamentos.

A análise das atitudes ambientais levantadas neste tópico permite observar que a gestão ambiental do GPA é voltada tanto para questões internas, a exemplo da reciclagem de resíduos próprios, como para a comunidade, ao oferecer aos cidadãos formas de descartar corretamente diversos tipos de materiais. De uma forma global, a empresa se mostra comprometida na corrida para o aumento da reciclagem dos resíduos, se engajando, inclusive, socialmente, ao implementar programas voltados aos entes da sociedade, como as cooperativas de catadores.

Calza et al. (2016) apontam que a identificação de um indicador efetivo que mensure a proatividade ambiental não é uma tarefa fácil, visto que há diferentes dimensões e manifestações que nem sempre são fáceis de serem acessadas. Ademais, muitas vezes cabe à empresas definir o degrau de prioridade que será atribuída às questões ambientais (Azzone et al., 1997). Neste estudo, apesar de apresentar diferenças no perfil dos seus programas, se comparada com as empresas analisadas por Kotzab et al., (2011), por exemplo, as ações de sustentabilidade predominantes nos Relatórios de Sustentabilidade do GPA demostram a adoção tanto de medidas proativas quanto de reativas voltadas para economia no uso de energia e água, redução de emissões e implementação de ações direcionadas aos produtos, às embalagens, ao transporte e aos resíduos.

Tais medidas são exemplos de inciativas que podem ser implementadas por outras empresas, especialmente as do comércio varejista, visto que empresas de um mesmo setor sofrem pressão do mesmo tipo de stakeholder (Azzone et al., 1997). Além disso, os exemplos de ações apresentados permitem contenção de custos/redução recursos econômicos empregados na operação, bem como geram menor impacto ambiental, combinação essencial para um progresso sustentável, econômica e ambientalmente, especialmente no longo prazo.

\section{Considerações finais}

Os relatórios anuais do Grupo Pão de Açúcar foram analisados neste estudo para a identificação de suas práticas de sustentabilidade predominantes, no período de 2010 a 2017. Por meio de uma análise interpretativa longitudinal, foram levantadas as ações predominantes do grupo em relação ao consumo de energia e água, ao descarte de água, à emissão de gases do efeito estufa (GEE) e à gestão de resíduos. Até 2013 a empresa 
utilizava o padrão GRI para confeccionar o citado relatório, mas, a partir de 2014, passou a utilizar a metodologia do United Nations Global Compact Principles.

Como resultado constatou-se que as ações de sustentabilidade predominantes no grupo se referem à utilização de fontes renováveis de energia, a exemplo da energia verde, ao desenvolvimento de projetos de eficiência energética, à implementação de ações para reduzir o consumo de água, à diminuição significativa de dejetos descartados de forma irregular, à elaboração de inventário de emissão de GEE, à substituição de gases nocivos utilizados na operação, à integração logística e à implementação da destinação de resíduos, tanto internos quanto externos à empresa.

Este estudo não observou aspectos econômico-financeiros ou sociais relacionados às atividades da empresa analisada. Entretanto, as ações de sustentabilidade predominantes no grupo analisado, sejam elas proativas ou reativas, relacionam-se com práticas operacionais que buscam otimizar o uso de recursos naturais ou diminuir o consumo destes e, consequentemente, permitem a redução dos custos relacionados às atividades do grupo, o que gera ganho econômico. Por outro lado, as práticas implementadas pelo grupo diminuem o impacto ambiental causado pela operação, contribuindo para o uso sustentável dos recursos naturais.

Os dados coletados foram aqueles que permitiram a comparabilidade dos achados. Foram identificadas medidas cuja aplicação pode ser viabilizada em outras empresas, especialmente as de varejo, cabendo a elas balancear o custo e o benefício relacionados à implementação de ações proativas de sustentabilidade ou agir reativamente, quando acionada legalmente, incorrendo o risco de operar irregularmente. Por outro lado, a generalização dos resultados deste estudo não é possível, visto que os dados provêm de uma única organização e de suas particularidades em determinado período.

A investigação de informações divulgadas de forma voluntária pelas empresas é uma limitação do estudo, pois elas podem implicar certo viés favorável à empresa: Deegan e Rankin (1997) apontam que, na média, as empresas divulgam o mínimo possível de informações negativas. Entretanto, o uso da análise interpretativa buscou reduzir esse viés por meio de um olhar crítico e comparativo.

Como sugestão de futura pesquisa, medidas implementadas tanto pelo GPA quanto por outros varejista poderiam ser investigadas, especialmente em suas unidades de pequeno porte, para o estabelecimento da comparabilidade das ações ambientais e ainda estendendo-se aos aspectos sociais e econômicos. Exemplos de ações ambientais poderiam ser elencados para as empresas de diferentes setores, verificando-se quais as particularidades permeiam as definições de estratégias sustentáveis em cada um deles.

\section{Conflito de interesses}

Os autores declaram não haver conflitos de interesse.

\section{Referências}

Aragón-Correa, J. A. Strategic proactivity and firm approach to the natural environment. Academy of Management Journal, v. 41, n. 5, p.556-567, 1998. https://doi.org/ $10.5465 / 256942$

Azzone, G.; Bianchi, R.; Mauri, R.; Noci, G. Defining operating environmental strategies: Programmes and plans within Italian industries. Environmental Management and Health, v. 8, n. 1, p. 4-19, 1997. https://doi.org/10.1108/09566169710159159 
Brasil. Lei no 12.305, de 2 de agosto de 2010. Institui a Política Nacional de Resíduos Sólidos; altera a Lei no 9.605, de 12 de fevereiro de 1998; e dá outras providências. Disponível em: <http://www.planalto.gov.br/ccivil_03/_ato2007-2010/2010/lei/ 112305.htm>. Acesso em: 27 nov. 2019.

Brasil, Bolsa e Balcão. Companhia Brasileira de Distribuição - Fato relevante. 2016. Disponível em: <http://www2.bmfbovespa.com.br/empresas/consbov/ArquivoCom Cabecalho.asp?motivo $=\&$ protocolo $=536142 \&$ funcao $=$ visualizar $\&$ site $=B>$. Acesso em: 27 nov. 2019.

Calza, F.; Profumo, G.; Tutore, I. Corporate ownership and environmental proactivity. Business Strategy and the Environment, v. 25, n. 6, p.369-389, 2016. https://doi.org/10.1002/bse.1873

CBD - Companhia Brasileira de Distribuição. 2015. Disponível em: <https://www.rad.cvm.gov.br/ENETCONSULTA/frmGerenciaPaginaFRE.aspx?NumeroSeq uencialDocumento=58356\&CodigoTipoInstituicao=2 >. Acesso em: 27 nov. 2019.

CBD - Companhia Brasileira de Distribuição. 2018. Disponível em: <https://www.rad.cvm.gov.br/ENETCONSULTA/frmGerenciaPaginaFRE.aspx?NumeroSeq uencialDocumento=73537\&CodigoTipoInstituicao=2 >. Acesso em: 27 nov. 2019.

Deegan, C.; Rankin, M. The materiality of environmental information to users of annual reports. Accounting, Auditing and Accountability Journal, v. 10, n. 4, p. 562-583, 1997. https://doi.org/10.1108/09513579710367485

González-Benito, J.; González-Benito, 0. A review of determinant factors of environmental proactivity. Business Strategy and the Environment, v. 15, n. 2, p. 87-102, 2006. https://doi.org/10.1002/bse.450

Grupo Pão de Açúcar. Relatórios Anuais - 2013. Disponível em: <http://relatorioanual 2013.gpabr.com/wp-content/uploads/2014/05/GPA_Simplificado_2013.pdf>. Acesso em: 27 nov. 2019.

Grupo Pão de Açúcar. Relatórios Anuais - 2016. Disponível em: <http://www.gpari. com.br/conteudo_pt.asp?idioma=0\&conta=28\&tipo=29910 >. Acesso em: 27 nov. 2019.

Grupo Pão de Açúcar. Relatórios Anuais - 2017. Disponível em: <http://www.gpari. com.br/conteudo_pt.asp?idioma=0\&conta=28\&tipo=29910 >. Acesso em: 27 nov. 2019.

Jones, P.; Comfort, D.; Hillier, D. UK retailing through the looking glass. International Journal of Retailing \& Distribution Management, v. 36, n. 7, p. 564-570, 2008. https://doi.org/10.1108/09590550810880606

Kolk, A. Sustainability, accountability and corporate governance: Exploring multinationals reporting practices. Business Strategy and the Environment, v. 17, n. 1, p. 1-15, 2008. https://doi.org/10.1002/bse.511

Kotzab, H.; Munch, H. M.; De Faultrier, B.; Teller, C. Environmental retail supply chains: When global Goliaths become environmental Davids. International Journal of Retail \& Distribution Management, v. 39, n. 9, p.658-681, 2011. https://doi.org/10.1108/ 09590551111159332

Matsumura, E.; Prakash, R.; Vera-Muñoz, S. Firm-value effects of carbon emissions and carbon disclosures. The Accounting Review, v. 89, n. 2, p, 695-724, 2014. https://doi.org/10.2139/ssrn.1921809

Roome, N. Developing environmental management strategies. Business Strategy and the Environment, v. 1, no. 1, p. 11-24, 1992. https://doi.org/10.1002/bse.3280010104 
São Paulo. Decreto no 8.468, de 8 de setembro de 1976. Aprova o regulamento da Lei $\mathrm{n}^{\mathbf{0}}$ 997, de 31 de maio de 1976, que dispõe sobre a prevenção e o controle da poluição do meio ambiente. Disponível em: <https://www.al.sp.gov.br/repositorio/legislacao/ decreto/1976/decreto-8468-08.09.1976.html>. Acesso em: 27 nov. 2019.

SBVC - Sociedade Brasileira de Varejo e Consumo. GPA lidera lista de empresas onde os brasileiros sonham trabalhar. 2017. Disponível em: <http://sbvc.com.br/lista-empresastrabalhar/>. Acesso em: 27 nov. 2019.

Severino, A. J. Metodologia do trabalho científico. 2000. Disponível em: <https://direitounitri.wordpress.com/materias/introducao-ao-direito/metodologia-dotrabalho-cientifico/>. Acesso em: 27 nov. 2019.

Sullivan, R.; Gouldson, A. The governance of corporate responses to climate change: An international comparison. Business Strategy and the Environment, v. 26, n. 4, p. 413-425, 2017. https://doi.org/10.1002/bse.1925

Tang, S.; Demeritt, D. Climate change and mandatory carbon reporting: Impacts on business process and performance. Business Strategy and the Environment, v. 27, n. 4, p. 437-455, 2018. https://doi.org/10.1002/bse.1985

Tinoco, J. E. P.; Kraemer, M. E. P. Contabilidade e gestão ambiental. 3. ed. São Paulo: Atlas, 2011.

Valero-Gil, J.; Rivera-Torres, P.; Garcés-Ayerbe, C. How is environmental proactivity accomplished? Drivers and barriers in firms' pro-environmental change process. Sustainability, v. 9, n. 8, 1327, 2017. https://doi.org/10.3390/su9081327

Waage, S. A.; Geiser, K.; Irwin, F.; Weissman, A. B.; Bertolucci, M. D.; Fisk, P.; Basile, G.; Cowan, S.; Cauley, H.; McPherson, A. Fitting together the building blocks for sustainability: A revised model for integrating ecological, social, and financial factors into business decision-making. Journal of Cleaner Production, v. 13, n. 12, p. 1145-1163, 2005. https://doi.org/10.1016/j.jclepro.2004.06.003

Informação da Licença: Este é um artigo Open Access distribuído sob os termos da Licença Creative Commons Attribution, que permite uso irrestrito, distribuição e reprodução em qualquer meio, desde que a obra original seja devidamente citada. 